\title{
Cognitive Correlates of Japanese Language (Hiragana) Reading Abilities among School-Aged very Low Birth Weight Children
}

\author{
Motohiro Isaki ${ }^{1,2}$, Tadahiro Kanazawa ${ }^{1}$, Toshihiko Hinobayashi ${ }^{1} \&$ Hiroyuki Kitajima ${ }^{3}$ \\ ${ }^{1}$ Graduate School of Human Sciences, Osaka University, Osaka, Japan \\ ${ }^{2}$ Japan Society for the Promotion of Science, Tokyo, Japan \\ ${ }^{3}$ Osaka Women's and Children's Hospital, Osaka, Japan \\ Correspondence: Motohiro Isaki, Faculty of Health and Medical Sciences, Aichi Shukutoku University, 2-9, \\ Katahira, Nagakute, Aichi, Japan. Tel: 81-561-62-4111. E-mail: isakimotohiro@gmail.com
}

Received: March 14, 2017

Accepted: March 31, 2017

Online Published: June 6, 2017

doi:10.5539/jedp.v7n2p33

URL: http://doi.org/10.5539/jedp.v7n2p33

\begin{abstract}
Previous studies have examined that the reading abilities of Very Low Birth Weight (VLBW) children are poorer than those of Normal Birth Weight (NBW) children. However, little is known about the cognitive functions that have been used to explain the reading problems in VLBW children. This study investigated that the effects of attention function on reading abilities in VLBW children. 23 VLBW children (mean age 9.1 years old) and 23 NBW children (mean age 9.2 years old) completed a reading test (containing word reading and non-word reading tasks), attention tasks, a phonological task and a naming task. The group differences were significant for the non-word reading task and attention tasks. Moreover, there were significant correlations between scores on the reading test and those on attention tasks. Multiple stepwise regression analysis suggested the reading scores were influenced by attention. These results of the present study suggest that attentional dyslexia is a characteristic of reading among VLBW children.
\end{abstract}

Keywords: very low birth weight children, preterm children, reading ability, attention

\section{Introduction}

Children born at Very Low Birth Weight (VLBW; $<1,500 \mathrm{~g}$ ) are at risk of poor academic attainment (Johnson, Wolke, Hennessy, \& Marlow, 2011; Litt et al., 2012). In a comparative survey of four countries - the United States, Canada, Germany and the Netherlands - over half of the extremely low birth weight children (children with birth weight under $1000 \mathrm{~g}$ ) needed special education services or had repeated a grade (Saigal et al., 2003). Severely poor academic attainment are associated with the risk of learning disabilities, and the incidence of learning disabilities in VLBW children is higher than that in Normal Birth Weight (NBW) children (Litt, Taylor, Klein, \& Hack, 2005; Saigal, Rosenbaum, Szatmari, \& Campbell, 1991). Moreover, Stanton-Chapman, Chapman, and Scott (2001) reported that the Apgar score (at 5 minutes after birth) correlated to the diagnosis of learning disabilities. The central symptom of learning disabilities is reading disorder. This study aimed to examine reading disorder among VLBW children.

\subsection{Reading Disorders of VLBW Children}

Many studies have found that the reading abilities of preterm/VLBW children are poorer than those of term/NBW children (Aarnoudse-Moens et al., 2009; Kovachy, Adams, Tamaresis, \& Feldman, 2015). However, the degree of severity of such reading problems differs across studies. These differences are caused by factors such as the types of reading assessments implemented and age of the sample. Extremely preterm children experienced equal deficits in both word and pseudo word reading at 11 years of age (Johnson et al., 2011). At school age, very preterm children performed more poorly on complex word reading than on simple word reading (Aarnoudse-Moens, Oosterlaan, Duivenvoorden, Bernard van Goudoever, \& Weisglas-Kuperus, 2011). Additionally, at 8 years of age, VLBW children had no deficit in reading accuracy, but exhibited impairments in reading speed (Guarini et al., 2010). Furthermore, while some research argues that the severity of reading disabilities reduces with age (Samuellson et al., 2006), the tendency of catch-up is limited to simple words, and no improvement was seen in complex words even with age (Aarnoudse-Moens et al., 2011). 
Most studies for reading in VLBW children have conducted with alphabetic languages. There are very few studies about reading abilities of VLBW children in non-alphabetic writing cultures. This research addresses the reading characteristics of VLBW children whose language is Japanese, which does not use alphabets. The Japanese language makes use of two character forms: kana characters (hiragana and katakana) and kanji. In $k a n a$, each character represents a single sound (a mora, to be precise). Two-mora words are expressed by combining two characters (see Figure 1). On the other hand, kanji expresses morphemes as well as sounds. A kanji has multiple pronunciations based on how it is used within a sentence (see Figure 2). Moreover, as compared to kana, kanji has a larger number of characters, more complex character forms. While Japanese children learn all kana characters in the first grade, they continue to study kanji until the completion of middle school (the ninth grade).

\subsection{Cognitive Function That Affect the Reading of VLBW Children}

$$
\text { うま }
$$

Figure 1. An example of Japanese hiragana

Note. A word spoken [uma] phonetically is written like Figure 1. The sound of the first letter of Figure 1a is [u], the sound of the last letter is [ma].

\section{孯}

Figure 2. An example of Japanese kanji

Note. A kanji like Figure 2 means horse. However, its pronunciation varies from [uma], [ba] to [ma], depending on the sentence.

The purpose of this study was to determine the core cognitive factors that influence the reading deficits among VLBW children. The double deficit hypothesis (Wolf \& Bowers, 1999) is a well-known explanation of the causes of dyslexia. The double deficit hypothesis suggests that poor readers show deficits in either phonological processing or naming speed, or in both. However, in recent years, there have been studies postulating that attention also influences reading abilities. Some studies indicate that children who experience reading difficulties have problems with visuospatial attention skills (Bosse, Tainturier, \& Valdois, 2007; Franceschini, Gori, Ruffino, Pedrolli, \& Facoetti, 2012). Given these findings, some researchers discuss the existence of attentional dyslexia, the causes of which differ from the dyslexic symptoms indicated by the double deficit hypothesis (Elliott \& Grigorenko, 2014). In addition, VLBW children have been reported to exhibit attention deficits (Anderson et al., 2011; Johnson \& Wolke, 2013; Mulder, Pitchford, Hagger, \& Marlow, 2009). Therefore, in studying the cause of reading impairments in VLBW children, attentional dyslexia may be a highly relevant concept.

Although, little is known about the cognitive functions that have been used to explain the reading problems in VLBW children, Wocadlo and Rieger (2007) examined the reading abilities of very preterm children using the double deficit hypothesis. They indicated that very preterm children who had difficulties with phonological processing or naming speed scored lower on reading accuracy than did very preterm children who did not have such difficulties. Further, those who had problems with both phonological processing and naming speed had even poorer reading scores. Thus, they revealed that the double deficit hypothesis was also applicable to the reading abilities of very preterm children. However, as their research did not make comparisons with full term and/or normal birth weight children, it has not been clarified whether VLBW children's scores on reading accuracy, phonological processing, and naming speed were lower than those of NBW children. Moreover, they suggested that attention is likely associated to their reading performance. Nevertheless, they did not conduct a separate test of attention.

Very few studies have compared VLBW children's phonological processing and naming speed with NBW children. With regard to phonological processing, VLBW children's scores have been shown to be lower than those of NBW children (Guarini et al., 2010; Johnson et al., 2011; T. Luu, Vohr, Allan, Schneider, \& Ment, 2011; Mullen et al., 2011). On the other hand, there have been no differences shown in naming speed between VLBW (or preterm) children and NBW (or term) children (Luu et al., 2009; Mullen et al., 2011; Myers et al., 2010; Saavalainen et al., 2006). 
Studies on VLBW children's brain functions suggest that attention influences reading. A study using magnetoencephalography (MEG) showed differences in the areas of brain activity between term children and preterm children. Preterm children particularly those with above average reading scores, demonstrated an over activation in the Broca's area, which is linked to language skills, and the prefrontal area, which is linked to attention. Further, poor activation of the prefrontal area was observed in preterm children who had reading difficulties (Frye et al., 2009). Nevertheless, only a few studies have clarified the relation between VLBW children's reading and attention using psychological measurement methods. While Anderson et al. (2011) suggest that the function of attention is related to VLBW children's reading, they did not conduct a reading test. According to Jaekel, Wolke, and Bartmann (2013), behavioral observation of inattention is related to academic outcomes. Yet, this study did not utilize any neuropsychological test of attention. In other words, very few studies on the relation between reading abilities and attentional functions of VLBW children used objective methods to investigate either of these abilities. Therefore, the present study aims to explore VLBW children's reading, and cognitive functions, which may have an influence on reading. It will explore the hypotheses that there are no group differences in the phonological processing and naming speed task scores, but that the scores of attention would be lower in VLBW children than that in NBW children; and phonological processing, naming speed and attention will influence reading abilities.

\section{Method}

\subsection{Participants}

Participants were 23 VLBW children $(<1,500 \mathrm{~g}$ birth weight, without intellectual disabilities or any apparent physical, visual, or hearing disabilities) and 23 NBW children (control group). All VLBW children were born in Hospital A (17 male, 6 female; mean age 9.1 years, mean birth weight $822.7 \mathrm{~g}$, mean gestation period 27.2 weeks). Table 1 indicates the perinatal characteristics of the VLBW group. The NBW group included 23 children who attended Primary School B (16 male, 7 female; mean age 9.2 years). All NBW children were healthy and with no history of perinatal problems and developmental disabilities. To make the groups as comparable as possible, we eliminated the participants with intellectual disabilities, cerebral palsy, or visual disabilities. Independent sample $t$ test revealed that VLBW group and NBW group sample did not differ significantly on their ages.

Table 1. Medical characteristics of the VLBW group

\begin{tabular}{lrr}
\hline & Mean & SD \\
\hline Birth weight (g) & 822.7 & 263.1 \\
Gestational age (weeks) & 27.2 & 3.0 \\
Head circumference at birth (cm) & 23.9 & 2.5 \\
Maternal age & 30.7 & 4.0 \\
Apgar 1 minute & 4.3 & 1.9 \\
Apgar 5 minute & 7.2 & 1.8 \\
Time on respirator (days) & 36.7 & 28.9 \\
Time on Oxygen (days) & 38.4 & 42.9 \\
\hline & & number \\
\hline intraventricular hemorrhage ${ }^{1)}$ & & 4 \\
periventricular leukomalacia & & 15 \\
bronchopulmonary dysplasia & & 19 \\
retinopathy of prematurity & & \\
\hline
\end{tabular}

Note 1. IVH grade is [.

In order to ensure the similarity of two groups' intelligence, we conducted the "block design" and "words" subtests of the Wechsler Intelligence Scale for Children-Fourth Edition (WISC-IV). This serves as a screening method to estimate group differences in intellectual abilities, and has also been used in a previous study targeting 
VLBW children (Kulseng et al., 2006). The groups did not show any differences at $5 \%$ level. Thus, the two samples did not differ in terms of intellectual abilities.

\subsection{Ethical Considerations and Recruitment Procedure}

This research obtained approval from the Osaka University Graduate School of Human Sciences Behavioral Sciences Research Ethics Committee (No. 24066). Additionally, for the sample of VLBW children, we received ethical approval from the Ethics Committee of Hospital A. An in-clinic psychologist explained this study during regular follow-ups at Hospital A, and we conducted assessments on children who consented to participate in this study. Furthermore, we also obtained approval to implement the study from the educational committee of Primary School B's municipality. The principal explained the study in a parent-teacher meeting, and consent forms were distributed. We conducted assessments on children who gave consent.

\subsection{Neuropsychological Measurement Items}

\subsubsection{Measurement of Reading Abilities}

Reading abilities were assessed using the "reading test" (Inagaki, 2010). In this task, the child needs to read aloud thirty words and non-words each, consisting of four hiragana characters. We recorded the time required for oral reading to indicate fluency, and the number of reading mistakes to assess accuracy of decoding.

\subsubsection{Measurement of Attention}

Visual search tasks are often utilized as measurements of attention in reading research. This study employed the Sky Search and Map Mission tasks from the Test of Everyday Attention for Children (TEA-Ch: Manly, Robertson, Anderson, \& Nimmo-Smith, 1999). TEA-Ch has not been standardized in Japan, so we translated as we went. In both tasks, the child is asked to search for target visual stimuli. While the Sky Search task has no set time limitations, the Map Mission task must be completed within one minute.

\subsubsection{Measurement of Phonological Processing Abilities}

There are no standardized tests to assess phonological processing in Japan. Phoneme deletion task and word reversal task are the recommended methods to assess phonological processing (Hara, 2003). The phoneme deletion task would be easy given the age of the participants in this study, and is thus highly likely to demonstrate a ceiling effect. So this study utilized the word reversal task. For this task, we used 15 words, containing two- to four-mora words. For example, [tanuki] (a word meaning raccoon) is a three-mora word, and in reverse, [kinuta] is a correct response. The word [zenbu] (meaning all) is a two-syllable word, but it is also a three-mora word. Therefore, in reverse, [bunze] is correct. Each stimulus word was presented vocally, and the children were asked to answer orally. We measured the number of mistakes.

\subsubsection{Measurement of Naming Speed Ability}

There is no standardized testing for naming speed ability in Japan. We utilised the Rapid Automated Naming (RAN) task by Kaneko, Uno, Haruhara (2004). We prepared three A4-size papers with ten line drawings and ten numbers placed randomly (each with different drawings and numbers). We measured the total time taken to name the contents on the three sheets. We also measured the number of mistakes. However, we did not record any mistakes in all the participants of this experiment.

\subsection{Statistical Analysis}

We performed independent $t$-tests to analyze group differences in the neuropsychological measurement tasks. To investigate the impact of cognitive functions that influence on word reading, we ran a multiple regression analysis using fluency scores of reading as the objective variable and the scores on Sky Search task, Map Mission task, word reversal task and RAN task as the explanatory variable. To assess model fit, we applied a stepwise procedure. We used Akaike's Information Criterion (AIC) to indicate good fit model. All statistical analyses were conducted using R3.1.2.

\section{Results}

\subsection{Results of Neuropsychological Measurement Items}

Table 2 indicates the measurement outcomes of the VLBW and NBW groups. 
Table 2. Scores for neuropsychological tests in VLBW and NBW children

\begin{tabular}{|c|c|c|c|c|c|c|}
\hline \multirow[t]{2}{*}{ Neuropsychological tests } & & \multicolumn{2}{|c|}{$\begin{array}{c}\text { VLBW } \\
(\mathrm{n}=23) \\
(\mathrm{m}=17, \mathrm{f}=6)\end{array}$} & \multicolumn{3}{|c|}{$\begin{array}{c}\text { NBW } \\
(\mathrm{n}=23) \\
(\mathrm{m}=16, \mathrm{f}=7)\end{array}$} \\
\hline & & Mean & $\mathrm{SD}$ & Mean & $\mathrm{SD}$ & $p$ \\
\hline \multirow[t]{2}{*}{ Reading accuracy } & Words (errors) & 0.3 & 0.5 & 0.2 & 0.4 & 0.24 \\
\hline & Nonwords (errors) & 2.3 & 2.3 & 1.1 & 1.1 & 0.02 \\
\hline \multirow[t]{2}{*}{ Reading fluency } & Words (sec) & 30.9 & 10.2 & 33.5 & 13.3 & 0.22 \\
\hline & Nonwords (sec) & 64.9 & 14.1 & 57.3 & 16.6 & 0.04 \\
\hline \multirow{4}{*}{$\begin{array}{l}\text { Phonological processing naming speed } \\
\text { attention }\end{array}$} & Word reversal (errors) & 2.3 & 2.2 & 2.6 & 2.6 & 0.38 \\
\hline & RAN (sec) & 44.9 & 10.7 & 41.5 & 8.2 & 0.15 \\
\hline & Sky search (duration/correct responses) & 6.2 & 2.2 & 5.5 & 1.1 & 0.09 \\
\hline & Map mission (correct responses) & 23.6 & 5.0 & 27.8 & 7.3 & 0.02 \\
\hline
\end{tabular}

\subsubsection{Reading Test}

There were no group differences in the scores of word reading task (accuracy: $t(44)=0.70, p=0.24$; fluency: $t(44)=0.76, p=0.22)$. On the other hand, the group differences were significant for non-word reading task (accuracy: $t(44)=2.19, p<0.05$; fluency: $t(44)=1.68, p<0.05$ ).

\subsubsection{Measurement Outcomes of Cognitive Functions}

There were no group differences in the scores of the word reversal task and RAN task, which are measured in the double deficit hypothesis of reading. The group differences were significant for Sky Search task and Map Mission task. In other words, the VLBW and NBW groups showed no significant differences in phonological processing task and naming speed task, but the VLBW group scored significantly lower than the NBW group in the attention tasks.

\subsection{Cognitive Functions That Influence Reading Abilities}

First, we explored the association between the scores of neuropsychological tasks. There were significant correlations between scores on reading test and those on double deficit (word reversal task and RAN task). With regard to selective attention measurements, there were significant correlations between scores on reading test and those on attention tasks (refer to Table 3).

Table 3. Correlations among neuropsychological tests

\begin{tabular}{|c|c|c|c|c|c|}
\hline Neuropsychological tests & 1 & 2 & 3 & 4 & 5 \\
\hline \multicolumn{6}{|l|}{ Reading fluency } \\
\hline \multicolumn{6}{|l|}{ 1. Words } \\
\hline 2. Nonwords & $0.75^{* * *}$ & & & & \\
\hline \multicolumn{6}{|l|}{ Double deficit for reading } \\
\hline 3. Words reversal (phonological processing) & $0.57 * * *$ & $0.53 * * *$ & & & \\
\hline 4. RAN task (naming speed) & $0.58 * * *$ & $0.57 * * *$ & $0.49 * * *$ & & \\
\hline \multicolumn{6}{|l|}{ Attention } \\
\hline 5. Sky serach & $0.36^{*}$ & $0.27 \dagger$ & -0.01 & 0.18 & \\
\hline 6. Map mission & -0.15 & $-0.31 *$ & 0.10 & -0.24 & $-0.30 *$ \\
\hline
\end{tabular}

Note. $\uparrow<0.1,{ }^{*} \mathrm{p}<0.05,{ }^{* *} \mathrm{p}<0.01,{ }^{* * *} \mathrm{p}<0.001$. 
Next, multiple stepwise regression analysis revealed the cognitive factors that influence reading scores. Table 4 indicates the outcomes. The word reversal, RAN, and Sky Search influenced word reading. The coefficient of determination for this model was $R^{2}=0.51$ at $0.1 \%$ level of significance $[F(3,42)=16.53, p<0.0001]$. Similarly, the word reversal, RAN, and Map Mission influenced non-word reading. The coefficient of determination for this model was $R^{2}=0.44$ at $0.1 \%$ level of significance $[F(3,42)=12.83, p<0.0001]$. Both these models suggest that the reading scores were influenced not only by phonological awareness and naming speed (the double deficit hypothesis) but also by attentional functions.

Table 4. Neuropsychological abilities independently associated with reading from multivariable stepwise regression analysis

\begin{tabular}{|c|c|c|c|c|}
\hline Variables & $R^{2}$ & $\beta$ & $95 \% C I$ & $p$ \\
\hline Words & 0.51 & & & \\
\hline Word reversal (phonological processing) & & 0.43 & {$[0.18-0.69]$} & 0.001 \\
\hline RAN task (naming speed) & & 0.32 & {$[0.07-0.56]$} & 0.01 \\
\hline Sky search (attention) & & 0.31 & {$[0.09-0.52]$} & 0.006 \\
\hline Nonwords & 0.44 & & & \\
\hline Word reversal (phonological processing) & & 0.41 & {$[0.15-0.68]$} & 0.003 \\
\hline RAN task (naming speed) & & 0.30 & {$[0.03-0.57]$} & 0.03 \\
\hline Map mission (attention) & & -0.28 & {$[-0.52--0.04]$} & 0.02 \\
\hline
\end{tabular}

Note. The $\beta$ value of Map mission is minus quantity because higher scores for Map mission task are indicative of better performance but lower scores for other tasks are indicative of better.

\section{Discussion}

This study rectified many of the limitations of previous research about reading abilities of VLBW children. By conducting many neuropsychological tests, we were able to provide new knowledge about reading abilities in VLBW children.

\subsection{Reading Abilities of VLBW Children}

VLBW children performed more poorly than NBW children on accuracy and fluency for non-word reading. In contrast, VLBW children did not score differently from NBW children for word reading. According to Shaywitz (2003), non-word reading is probably the best measurement of pure decoding abilities. These findings suggest that VLBW children exhibit deficits in decoding.

Guarini et al. (2010) did not show significant differences of accuracy for non-word reading between VLBW and NBW group. The sample used in Guarini et al.'s (2010) study had a mean birth weight of $1243 \mathrm{~g}$ and a mean gestational period of 30.4 weeks. Whereas, the sample used in this study had a mean birth weight of $822.7 \mathrm{~g}$ and a mean gestational period of 27.2 weeks. In other words, the children in this study were born smaller and earlier, which may have contributed to further deficits in accuracy. For example, the prevalence rate of reading disorders in late preterm (gestational period over 34 weeks but under 37 weeks) children was not significantly different from that in term children (Harris et al., 2013). Additionally, a meta-analysis on the reading abilities of preterm children with gestational age under 32 weeks found that the smaller the mean gestational age of the sampled children in the data, the lower their reading abilities were (Kovachy et al., 2015). Moreover, a meta-analysis of children with gestational age under 33 weeks and birth weight under $1500 \mathrm{~g}$ revealed a correlation between gestational age and birth weight, and reading scores (Aarnoudse-Moens, Weisglas-Kuperus, van Goudoever, \& Oosterlaan, 2009). In other words, these findings suggest that the smaller the gestational age and lighter the birth weight, the higher is the risk of reading disorders. We consider that the differences in outcomes of our study and those of Guarini et al. (2010) are due to the differences in the birth weight and gestational age of the VLBW children sampled.

Next, we consider the reasons for the different outcomes of fluency for word reading in this study and that of Guarini et al. (2010). The Italian version of the reading test, which Guarini et al. used for their study, included 112 words and 48 non-words, while the Japanese version of the reading test used in this research had 30 words 
each for words and non-words. Such differences in the number of items in the test could have influenced the outcome of fluency. In other words, the fluency of VLBW children could deteriorate as the number of items increase. This is due to the fact that VLBW children have difficulties maintaining attention, as indicated by preceding studies (Anderson et al., 2011; Mulder et al., 2009). The difficulties of fluency in VLBW children may not be apparent while they read fewer words, as observed in the present study; but when the number of words increases, their fluency deteriorates as they are unable to maintain the attention required for reading.

\subsection{Cognitive Functions That Influence VLBW Children's Reading}

According to double deficit hypothesis (Wolf \& Bowers, 1999), phonological processing and naming speed relate to reading ability. Targeting 8 year-old very preterm children, Wocadlo and Rieger (2007) clarified that the double deficit hypothesis also applies to preterm children. However, their study did not compare with the term groups, and did not clarify if preterm children's phonological processing and naming speed are impaired. Therefore, the present study conducted comparisons between NBW and VLBW children, and examined whether there are group differences in phonological processing and naming speed abilities. Additionally, this study also investigated the relationship between attention and reading.

This study showed that the scores of phonological processing and naming speed in VLBW children were not different from those of NBW children. With regards to naming speed, group differences have not been reported in preceding studies either (Luu et al., 2009; Mullen et al., 2011; Saavalainen et al., 2006), thus matching the outcome of the present study. Confirming that naming speed abilities are less likely to be impaired in school-aged VLBW children.

With regard to phonological processing abilities, previous studies (Guarini et al., 2010; Johnson et al., 2011; Luu, Vohr, Allan, Schneider, \& Ment, 2011; Mullen et al., 2011) recognize group differences, which was not reflected in the present findings. This inconsistency between previous studies and the present study may relate the character system of language. While the previous studies targeted children in alphabetic writing cultures, the present study targeted children in the Japanese language (non-alphabetic) culture. In recent years, some researchers have argued that phonological processing may not have as much influence on reading abilities in the Japanese language (Welty, Menn, \& Oishi, 2014). On the other hand, some studies have reported phonological processing scores to be correlated to the fluency and accuracy scores for reading (Seki, Kassai, Uchiyama, \& Koeda, 2008). This demonstrates a need for further research regarding phonological processing in the Japanese language.

Next, this research hypothesized that attention relate to VLBW children's reading, and we were able to verify this hypothesis. The link between preterm children's reading abilities and attention has been indicated in studies using brain imaging (Frye et al., 2009, 2010), but there are few studies that indicate this relationship using a psychological measurement. The present study supports findings of a study conducted by Frye et al. $(2009,2010)$ using psychological methods. Our results showed that the score of selective attention in neuropsychological test influenced reading abilities. Valdois et al. (2011) reported that there are children who have reading disorders due to attention problems despite not having a phonological processing problem (Valdois et al., 2011). In other words, the results of the present study suggest that attentional dyslexia (Elliott \& Grigorenko, 2014) might be a characteristic of reading among VLBW children.

\subsection{The Limitations of the Present Study and Future Prospects}

The present study investigated the reading abilities of Japanese VLBW children, but the reading tests were limited to the reading of hiragana, and did not include kanji. As compared to hiragana, kanji has complex character forms. As VLBW children scored lower on complex word reading as compared to simple word reading in alphabetical writing forms (Aarnoudse-Moens et al., 2011), they may score lower on kanji reading than on hiragana reading. Furthermore, kanji uses letters from the Chinese language. Interestingly, the brain areas activated during reading are different for readers of an alphabetic language and the Chinese language, with Chinese language readers demonstrating more brain activity in the left middle frontal gyrus. This area is related to visual attention, and suggests that more visual attention is required to read the complex letters of the Chinese language than for reading an alphabetical language (Siok, Perfetti, Jin, \& Tan, 2004). In other words, it is possible that reading kanji could require more visual attention than reading hiragana does. The need to clarify the relationship between kanji reading and attention among VLBW children is a central theme in future research. 


\section{Acknowledgements}

This study was supported by the Japan Society for the Promotion of Science (JPSS KAKENHI Grant Number JP 26•1571). We would like to thank pediatrician Shinya Hirano and psychologists Etsuyo Yamamoto and Machiko Tajima in Osaka Women's and Children's Hospital, in addition to the families who participated in this study.

\section{References}

Aarnoudse-Moens, C. S. H., Weisglas-Kuperus, N., van Goudoever, J. B., \& Oosterlaan, J. (2009). Meta-analysis of neurobehavioral outcomes in very preterm and/or very low birth weight children. Pediatrics, 124(2), 717-728. https://doi.org/10.1542/peds.2008-2816

Aarnoudse-Moens, C., Oosterlaan, J., Duivenvoorden, H., Bernard van Goudoever, J., \& Weisglas-Kuperus, N. (2011). Development of preschool and academic skills in children born very preterm. The Journal of Pediatrics, 158(1), 51-56. https://doi.org/10.1016/j.jpeds.2010.06.052

Anderson, P. J., De Luca, C. R., Hutchinson, E., Spencer-Smith, M. M., Roberts, G., \& Doyle, L. W. (2011). Attention problems in a representative sample of extremely preterm/extremely low birth weight children. Developmental Neuropsychology, 36(1), 57-73. https://doi.org/10.1080/87565641.2011.540538

Bosse, M. L., Tainturier, M. J., \& Valdois, S. (2007). Developmental dyslexia: The visual attention span deficit hypothesis. Cognition, 104(2), 198-230. https://doi.org/10.1016/j.cognition.2006.05.009

Elliott, J. G., \& Grigorenko, E. L. (2014). The dyslexia debate. New York: Cambridge University Press. https://doi.org/10.1017/CBO9781139017824

Franceschini, S., Gori, S., Ruffino, M., Pedrolli, K., \& Facoetti, A. (2012). A causal link between visual spatial

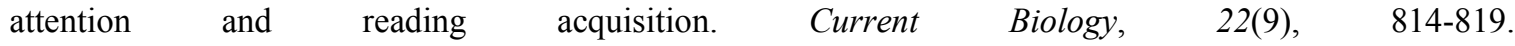
https://doi.org/10.1016/j.cub.2012.03.013

Frye, R. E., Hasan, K., Malmberg, B., Desouza, L., Swank, P., Smith, K., \& Landry, S. (2010). Superior longitudinal fasciculus and cognitive dysfunction in adolescents born preterm and at term. Developmental Medicine and Child Neurology, 52(8), 760-766. https://doi.org/10.1111/j.1469-8749.2010.03633.x

Frye, R. E., Malmberg, B., deSouza, L., Swank, P., Smith, K., \& Landry, S. (2009). Increased prefrontal activation in adolescents born prematurely at high risk during a reading task. Brain Research, 1303, 111-119. https://doi.org/10.1016/j.brainres.2009.09.091

Guarini, A., Sansavini, A., Fabbri, C., Savini, S., Alessandroni, R., Faldella, G., \& Karmiloff-Smith, A. (2010). Long-term effects of preterm birth on language and literacy at eight years. Journal of Child Language, 37, 865-885. https://doi.org/10.1017/S0305000909990109

Harris, M. N., Voigt, R. G., Barbaresi, W. J., Voge, G. A., Killian, J. M., Weaver, A. L., ... Katusic, S. K. (2013). ADHD and Learning Disabilities in Former Late Preterm Infants: A Population-Based Birth Cohort. Pediatrics, 132(3), 630-636. https://doi.org/10.1542/peds.2012-3588

Jaekel, J., Wolke, D., \& Bartmann, P. (2013). Poor attention rather than hyperactivity/impulsivity predicts academic achievement in very preterm and full-term adolescents. Psychological Medicine, 43, 183-196. https://doi.org/10.1017/S0033291712001031

Johnson, S., \& Wolke, D. (2013). Behavioural outcomes and psychopathology during adolescence. Early Human Development, 89(4), 199-207. https://doi.org/10.1016/j.earlhumdev.2013.01.014

Johnson, S., Wolke, D., Hennessy, E., \& Marlow, N. (2011). Educational outcomes in extremely preterm children: Neuropsychological correlates and predictors of attainment. Developmental Neuropsychology, 36(1), 74-95. https://doi.org/10.1080/87565641.2011.540541

Kovachy, V. N., Adams, J. N., Tamaresis, J. S., \& Feldman, H. M. (2015). Reading abilities in school-aged preterm children: A review and meta-analysis. Developmental Medicine \& Child Neurology, 57(5), 410-419. https://doi.org/10.1111/dmen.12652

Kusleng, S., Jennekens-Schinkel, A., Naess, P., Romundstad, P., Indredavik, M., Vik, T., \& Brubakk, A.-M. (2006). Very-low-birthweight and term small-for-gestational-age adolescents: Attention revisited. Acta Paediatrica, 95(2), 224-230. 
Litt, J. S., Taylor, H. G., Margevicius, S., Schluchter, M., Andreias, L., \& Hack, M. (2012). Academic achievement of adolescents born with extremely low birth weight. Acta Paediatrica (Oslo, Norway: 1992), 101, 1240-1245. https://doi.org/10.1111/j.1651-2227.2012.02790.x

Litt, J., Taylor, H. G., Klein, N., \& Hack, M. (2005). Learning Disabilities in Children with Very Low Birthweight: And Educational Interventions. Journal of Learning Disabilities, 38, 130-141. https://doi.org/10.1177/00222194050380020301

Luu, T. M., Ment, L. R., Schneider, K. C., Katz, K. H., Allan, W. C., \& Vohr, B. R. (2009). Lasting effects of preterm birth and neonatal brain hemorrhage at 12 years of age. Pediatrics, 123, 1037-1044. https://doi.org/10.1542/peds.2008-1162

Luu, T. M., Vohr, B. R., Allan, W., Schneider, K. C., \& Ment, L. R. (2011). Evidence for catch-up in cognition and receptive vocabulary among adolescents born very preterm. Pediatrics, 128(2), 313-322. https://doi.org/10.1542/peds.2010-2655

Manly, T., Robertson, I. H., Anderson, V., \& Nimmo-Smith, I. (1999). The Test of Everyday Attention for Children. London: Pearson.

Mulder, H., Pitchford, N. J., Hagger, M. S., \& Marlow, N. (2009). Development of executive function and attention in preterm children: A systematic review. Developmental Neuropsychology, 34(4), 393-421. https://doi.org/10.1080/87565640902964524

Mullen, K. M., Vohr, B. R., Katz, K. H., Schneider, K. C., Lacadie, C., Hampson, M., ... Ment, L. R. (2011). Preterm birth results in alterations in neural connectivity at age 16 years. NeuroImage, 54(4), 2563-2570. https://doi.org/10.1016/j.neuroimage.2010.11.019

Myers, E. H., Hampson, M., Vohr, B., Lacadie, C., Frost, S. J., Pugh, K. R., ... Ment, L. R. (2010). Functional connectivity to a right hemisphere language center in prematurely born adolescents. NeuroImage, 51(4), 1445-1452. https://doi.org/10.1016/j.neuroimage.2010.03.049

Saavalainen, P., Luoma, L., Bowler, D., Timonen, T., Määttä, S., Laukkanen, E., \& Herrgård, E. (2006). Naming skills of children born preterm in comparison with their term peers at the ages of 9 and 16 years. Developmental Medicine \& Child Neurology, 48, 28-32. https://doi.org/10.1017/s0012162206000077

Saigal, S., den Ouden, L., Wolke, D., Hoult, L., Paneth, N., Streiner, D. L., ... Pinto-Martin, J. (2003). School-age outcomes in children who were extremely low birth weight from four international population-based cohorts. Pediatrics, 112, 943-950. https://doi.org/10.1542/peds.112.4.943

Saigal, S., Rosenbaum, P., Szatmari, P., \& Campbell, D. (1991). Learning disabilities and school problems in a regional cohort of extremely low birth weight (less than $1000 \mathrm{G}$ ) children: A comparison with term controls. Journal of Developmental and Behavioral Pediatrics: JDBP, 12, 294-300. https://doi.org/10.1097/00004703-199110000-00002

Samuelsson, S., Finnström, O., Flodmark, O., Gäddlin, P. O., Leijon, I., \& Wadsby, M. (2006). A longitudinal study of reading skills among very-low-birthweight children: Is there a catch-up? Journal of Pediatric Psychology, 31, 967-977. https://doi.org/10.1093/jpepsy/jsj108

Sansavini, A., Guarini, A., Savini, S., Broccoli, S., Justice, L., Alessandroni, R., \& Faldella, G. (2011). Longitudinal trajectories of gestural and linguistic abilities in very preterm infants in the second year of life. Neuropsychologia, 49, 3677-3688. https://doi.org/10.1016/j.neuropsychologia.2011.09.023

Seki, A., Kassai, K., Uchiyama, H., \& Koeda, T. (2008). Reading ability and phonological awareness in Japanese children with dyslexia. Brain and Development, 30, 179-188. https://doi.org/10.1016/j.braindev.2007.07.006

Shaywitz, S. (2003). Overcoming dyslexia. A new and complete science-based program for reading problems at any level. New York: Random House.

Stanton-Chapman, T. L., Chapman, D. A., \& Scott, K. G. (2001). Identification of Early Risk Factors for Learning Disabilities. Journal of Early Intervention, 24(3), 193-206. https://doi.org/10.1177/10538151010240030501

Valdois, S., Bidet-Ildei, C., Lassus-Sangosse, D., Reilhac, C., N'guyen-Morel, M. A., Guinet, E., \& Orliaguet, J. P. (2011). A visual processing but no phonological disorder in a child with mixed dyslexia. Cortex, 47(10), 1197-1218. https://doi.org/10.1016/j.cortex.2011.05.011 
Welty, Y. T., Menn, L., \& Oishi, N. (2014). Developmental Reading Disorders in Japan—Prevalence, Profiles, and Possible Mechanisms. Topics in Language Disorders, 34(2), 121-132. https://doi.org/10.1097/TLD.0000000000000014

Wocadlo, C., \& Rieger, I. (2007). Phonology, rapid naming and academic achievement in very preterm children at eight years of age. Early Human Development, 83, 367-377. https://doi.org/10.1016/j.earlhumdev.2006.08.001

Wolf, M., \& Bowers, P. G. (1999). The double-deficit hypothesis for the developmental dyslexias. Journal of Educational Psychology, 91, 415-438. https://doi.org/10.1037/0022-0663.91.3.415

\section{Copyrights}

Copyright for this article is retained by the author(s), with first publication rights granted to the journal.

This is an open-access article distributed under the terms and conditions of the Creative Commons Attribution license (http://creativecommons.org/licenses/by/4.0/). 